OPEN 2 ACCESS Freely available online

http://www.banglajol.info/index.php/BJID/index

Original Article

Bangladesh Journal of Infectious Diseases

December 2015, Volume 2, Number 2

ISSN (online) 2411-670X

ISSN (Print) 2411-4820

\title{
Diagnostic Value of Sputum Eosinophil Counts in Patients with Cough Variant Asthma
}

\author{
SK Shahinur Hossain ${ }^{1}$, Md. Safiul Islam ${ }^{2}$, Md. Mustafizur Rahman ${ }^{3}$, Shubhashish De ${ }^{4}$
}

${ }^{1}$ Assistant Professor, Department of Respiratory Medicine at National Institute of Diseases of the Chest and Hospital, Dhaka, Bangladesh; Medical Officer, Department of Respiratory Medicine at National Institute of Diseases of the Chest and Hospital, Dhaka, Bangladesh; ${ }^{3}$ OSD, Directorate General of Health Services, Ministry of Health \& Family Welfare, Dhaka, Bangladesh;

${ }^{4}$ Assistant Register, Department of Medicine, Shaheed Tajuddin Ahmed Medical College, Gajipur, Bangladesh

[Received: 1 January 2015; Accepted: 15 March 2015; Published: 1 December 2015]

\begin{abstract}
Background: Diagnosis of cough variant asthma is very important. Objectives: The purpose of the present study was to measure the diagnostic value of eosinophil counts in sputum for the diagnosis of cough variant asthma patients. Methodology: This descriptive type of cross-sectional study was carried out in the Department of Respiratory Medicine at National Institute of Diseases of the Chest and Hospital (NIDCH), Dhaka, Bangladesh from September 2014 to August 2015 for a period of one year. Patients presented with cough variant asthma attending in NIDCH were selected as study population. Methacholine challenge test was performed to diagnosis of cough variant asthma. After Methacholine test, patient was encouraged to produced sputum. Sputum was collected in a plastic container and labeled accordingly and was sent to microbiology department of NIDCH for sputum eosinophil counts. Result: A total number of 50 patients were recruited for this study. The mean age \pm SD was found $19.1 \pm 7.6$ years. 20 patients had leucocytosis. 96\% patients had sputum eosinophil, 90\% patients had $>3 \%$ sputum eosinophil and $10 \%$ patients had $\leq 3 \%$ sputum eosinophil count. All patients had trigger factor with negative CFT for Filaria and increased serum IgE. Conclusion: In conclusion increased eosinophil count in sputum is diagnostic tool in cough variant asthma. [Bangladesh Journal of Infectious Disease 2015;2(2):37-41]

Keywords: Cough variant asthma; sputum; eosinophil counts; diagnostic value

[How to Cite This Article: Hossain SKS, Islam MS, Rahman MM, Dey S. Diagnostic Value of Sputum Eosinophil Counts in Patients with Cough Variant Asthma. Bangladesh J Infect Dis 2015;2(2):37-41]

Corresponding author: Dr. Sk Shahinur Hossain, Assistant Professor, Department of Respiratory Medicine, National Institute of Diseases of the Chest and Hospital, Dhaka, Bangladesh; Email: dr.parvez47@gmail.com; Cell no.: +8801711355872

Conflict of Interest: Authors have declared no conflict of interest.

Contributions to authors: SKSH \& MSI have contributed from protocol preparation to manuscript writing as well as in data collection. MMR \& SD have prepared and have revised the manuscript.
\end{abstract}

\section{Introduction}

Patients with cough variant asthma (CVA) are usually presented with a chronic cough which is the sole symptom ${ }^{1}$. It responds to bronchodilator treatment and show airway hyperresponsiveness ${ }^{2}$. Cough variant asthma is one of the most common causes of chronic cough ${ }^{2}$. It has been considered a precursor $^{3}$ and a variant form of classic asthma with typical symptoms of wheezing and dyspnea ${ }^{4}$. Several studies have examined mechanistic differences between CVA and classic asthma ${ }^{5-7}$. 
People with cough-variant asthma often have no other "classic" asthma symptoms, such as wheezing or shortness of breath ${ }^{8}$. CVA is somewhat difficult to diagnose because the cough may be the only symptom, with normal physical examination, chest $\mathrm{X}$ - rays, and spirometry. There are three recommended ways to diagnose the cough variant asthma of variability in lung function or of air way hyper-responsiveness and search for sputum eosinophils ${ }^{9}$. Positive methacholine challenge test will indicate asthma; however, methacholine test is also positive in a wide variety of other diseases. This test also causes a false negative response. Methacholine challenge testing is more useful in excluding a diagnosis of asthma than in establishing one because its negative predictive power is greater than its positive predictive power ${ }^{10}$. Therefore, the present study was undertaken to measure the diagnostic value of eosinophil counts in sputum for the diagnosis of cough variant asthma patients.

\section{Methodology}

This descriptive type of cross-sectional study was carried out in the Department of Respiratory Medicine at National Institute of Diseases of the Chest and Hospital (NIDCH), Dhaka, Bangladesh from September 2014 to August 2015 for a period of one year. Sputum examination was performed in the Microbiology Department of National Institute of Diseases of the Chest and Hospital, Dhaka, Bangladesh. Purposive sampling technique was used to select the patients. Patients with the age of more than or equal to 30 years who were suffering from chronic cough for more than 8 weeks with positive methacholine challenge test were included as study population. Smokers, patients having COPD, patients having other causes of chronic cough like post nasal drip, gastro-esophageal reflux disease, ILD, heart failure, use of ACE inhibitor drugs were excluded from this study. In the first phase a standard questionnaire was designed with a view to collect data. Informed written consent was taken from each patient. Initial evaluation of the patient by history and clinical examination was performed and recorded in the preformed data sheet. Subjects were explained the procedure. Baseline spirometry was performed before methacholine used. Prepared 10 doubling concentrations of methacholine were followed 0.03 , $0.06,0.125,0.25,0.50,1,2,4,8,16 \mathrm{mg} / \mathrm{dL}^{2}$. Methacholine challenge test was performed ${ }^{1}$. Concentration of methacholine was started from minimum concentration $0.03 \mathrm{mg} / \mathrm{dL}$ and was gradually increased the dose up to the level at which $20.0 \%$ fall in $\mathrm{FEV}_{1}$ was observed from base line or the highest concentration $(16 \mathrm{mg} / \mathrm{dL})$ of the drug had been delivered. A total of 10 doses were given if the entire procedure was finished without a positive response. Another spirometry was performed and result was recorded. Patients were resuscitated by nebulised bronchodilator. The procedure was performed in the respiratory laboratory of NIDCH, Dhaka. During sputum assays, the volume was assessed by the size and number of plugs: a cumulative size of $4.5 \times 9 \mathrm{~mm}$ was estimated to be necessary to perform all investigation. Differential counts were determined by counting 200 non-squamous cells on each sputum slide. Statistical analyses were carried out by using the Statistical Package for Social Sciences version 16.0 for Windows (SPSS Inc., Chicago, Illinois, USA). Continuous variables were expressed as mean, standard deviation, and categorical variables as frequencies and percentages.

\section{Results}

A total 50 patients were included in the study. Majority $(44.0 \%)$ patients were in the age group of 21 to 30 years followed by the age group of 11 to 20 years $(38.0 \%)$. The mean age was found 19.1 \pm 7.6 years with range from 8 to 30 years (Table $1)$.

Table 1: Age distribution in the study patients $(\mathbf{n}=50)$

\begin{tabular}{lcc}
\hline Age Group & \multicolumn{2}{r}{ Frequency Percentage } \\
\hline Less Than 10 Years & 9 & 18.0 \\
11 to 20 Years & 19 & 38.0 \\
21 to 30 Years & 22 & 44.0 \\
\hline Total & $\mathbf{5 0}$ & $\mathbf{1 0 0 . 0}$ \\
\hline *Mean \pm SD $=18.9 \pm 7.2 ;$ & Range (min-max) $=8$ to 30 \\
years &
\end{tabular}

More than 11000/cumm was counted as leucocytosis. In this study leucocytosis was found in $10(20.0 \%)$ cases and the rest $40(80.0 \%)$ was presented without any leucocutosis (Table 2).

Table 2: Leucocytosis in the Study Patients $(\mathbf{n}=50)$

\begin{tabular}{|c|c|c|}
\hline $\begin{array}{l}\text { Leucocytosis } \\
(>11000 / \mathrm{cmm})\end{array}$ & Freque & ercentag \\
\hline Present & $\overline{10}$ & 20.0 \\
\hline Absent & 40 & 80.0 \\
\hline Total & 50 & 100.0 \\
\hline
\end{tabular}

In this study more than $6.0 \%$ eosinophil count in blood was designated as eosinophilia. Therefore, 
eosinophilia was found in $16(32.0 \%)$ cases and the rest $34(68.0 \%$ ) cases were normal eosinophil count (Table 3).

Table 3: Eosinophilia in the Study Patients $(\mathbf{n}=\mathbf{5 0})$

\begin{tabular}{lcc}
\hline $\begin{array}{l}\text { EosinophiliaFrequencyPercentage } \\
\text { (> 6\%) }\end{array}$ \\
\hline Present & 16 & 32.0 \\
Absent & 34 & 68.0 \\
Total & $\mathbf{5 0}$ & $\mathbf{1 0 0 . 0}$ \\
\hline
\end{tabular}

It was observed that majority $28(56.0 \%)$ patients had normal total circulating eosinophil $(<400 / \mathrm{cmm})$ and $22(44.0 \%)$ had increased $(>400 / \mathrm{cmm})$ total circulating eosinophil (Figure I).

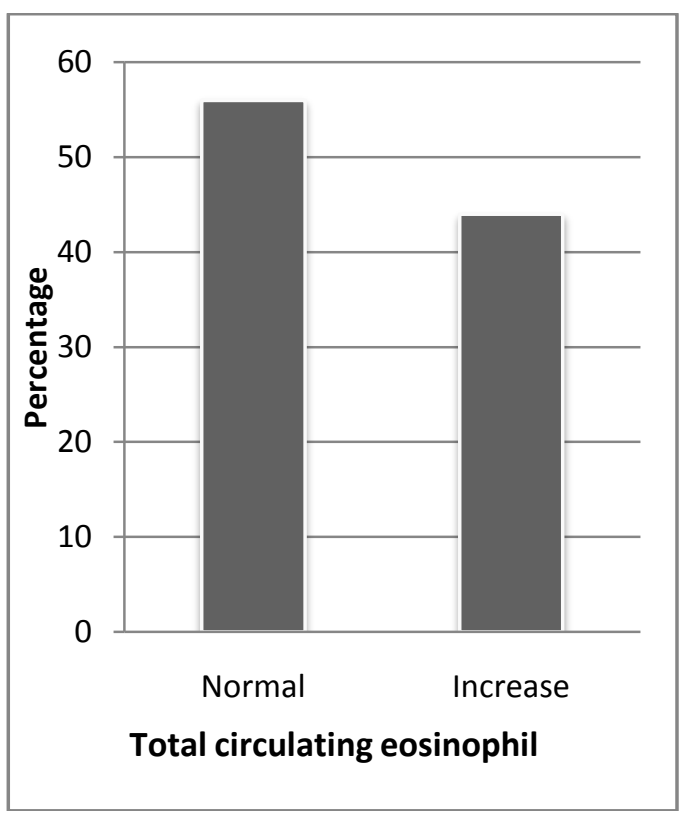

Figure I: Total Circulating Eosinophil in the Study Patients

In this study all (100.0\%) patients had negative CFT for filarial (Table 4).

Table 4: CFT for filaria in the study patients $(\mathbf{n}=50)$

\begin{tabular}{lcc}
\hline CFT for Filaria & Frequency & Percentage \\
\hline Positive & 0 & 0.0 \\
Negative & 50 & 100.0 \\
Total & $\mathbf{5 0}$ & $\mathbf{1 0 0 . 0}$ \\
\hline
\end{tabular}

Table 5 showed that all $(100.0 \%)$ patients had increased serum IgE level (Table 5).
Table 5: Serum IgE level in the Study Patients $(\mathbf{n}=\mathbf{5 0})$

\begin{tabular}{lcc}
\hline Serum Ig E level & Frequency & Percentage \\
\hline Normal $(<200 \mathrm{IU} / \mathrm{ml})$ & 0 & 0.0 \\
Increased $(>200 \mathrm{IU} / \mathrm{ml})$ & 50 & 100.0 \\
Total & $\mathbf{5 0}$ & $\mathbf{1 0 0 . 0}$ \\
\hline
\end{tabular}

It was observed that $48(96.0 \%)$ patients had Eosinophil in sputum (Figure II).



Figure II: Pie chart showing Sputum Eosinophil in the Study Patients

In this study more than $3 \%$ eosinophil count in sputum was found in $45(90.0 \%)$ patients and $5(10.0 \%)$ patients had less than or equal to $3 \%$ eosinophil count in sputum (Table 6).

Table 6: Sputum Eosinophil Count in the Study Patients $(\mathbf{n}=50)$

\begin{tabular}{lcc}
\hline Sputum eosinophil count & Frequency & Percentage \\
\hline Eosinophil count $>3 \%$ & 45 & 90.0 \\
Eosinophil count $\leq 3 \%$ & 5 & 10.0 \\
Total & $\mathbf{5 0}$ & $\mathbf{1 0 0 . 0}$ \\
\hline
\end{tabular}

\section{Discussion}

Patients with CVA are less sensitive and less reactive to inhaled methacholine than are those with classic asthma ${ }^{11}$. Coughing is more frequent during methacholine-induced bronchoconstriction in the CVA group, whereas wheezes is more frequent in the classic asthma group at the end of methacholine inhalation $^{12}$.

This present observational study has been carried out with an aim to find out the easy technique for diagnosis of cough variant asthma and to determine the eosinophil count in patients with cough variant asthma. A total of 50 patients are enrolled in this 
study. In this study it has been observed that $42.0 \%$ patients belong to age 21 to 30 years and the mean age is $19.1 \pm 7.6$ years with range from 8 to 30 years. Yoo et $\mathrm{al}^{13}$ have showed that the mean $( \pm \mathrm{SD})$ age is $11.4 \pm 2.2$ years, which is lesser with the present study. On the other hand Al-Moamary et $\mathrm{al}^{14}$ have found that the mean age is $32.05 \pm 10.87$ years. The high mean age and age range has been obtained may be due to geographical variation as well as racial influences.

In this study $10(20.0 \%)$ patients had increased leucocyte count. Matsuoka et $\mathrm{al}^{15}$ showed a total leukocyte count of 8200 cells $/ \mathrm{mm}^{3}$ with $65.4 \%$ neutrophils and $3.0 \%$ eosinophils. In this series it was observed that nearly one third $(32.0 \%)$ patients had Eosinophilia. Harish and Suryanarayana ${ }^{16}$ observed $61 \%$ had eosinophilia and 39.0\% had normal counts. In this present study $56.0 \%$ patients had normal total circulating eosinophil and $44.0 \%$ had increased total circulating eosinophil. Increased eosinophil counts have also been reported in a large proportion of patients with asthma treated with inhaled corticosteroids observed by Richter et $\mathrm{al}^{17}$. In this present study it has been observed that all $(100.0 \%)$ patients have negative CFT for filaria and all $(100.0 \%)$ patients have increased serum $\operatorname{IgE}$ level. Surprisingly, a correlation with total serum $\operatorname{IgE}$ has been demonstrated in a study by Good et $\mathrm{al}^{18}$ in which bronchoscopy has been used to assess asthma phenotypes. Therefore, total serum $\operatorname{IgE}$ is not useful as a diagnostic marker for eosinophilic asthma. In this present study it was observed that 96.0\% patients had sputum Eosinophil. Harish and Suryanarayana ${ }^{16}$ obtained in their study that $87.5 \%$ subjects had sputum eosinophilia. In this current study, study patients is divided into two category on the basis of the eosinophil count in sputum as follows, sputum eosinophil count $>3 \%$, and $\leq 3 \%$ category, it was observed that $90.0 \%$ populations had sputum eosinophil count $>3 \%$ and $10 \%$ had $\leq$ $3 \%$ sputum eosinophil count. Alvarez et al ${ }^{6}$ have reported that an increase of eosinophil count $(>3.2 \%)$ in induced sputum has been observed in three out of six patients with chronic cough and bronchial hyperresponsiveness, who might be given a diagnosis of $\mathrm{CVA}^{5}$. Ayik et $\mathrm{al}^{2}$ mentioned that sputum eosinophilia greater than $3.0 \%$ is present in $33.3 \%$ patients and the patients have been diagnosed as eosinophilic bronchitis. Niimi et $\mathrm{al}^{3}$ showed 5 out of 6 patients a marked increase of eosinophils in sputum more than $80 \%$ of the nucleated cells. Godon et $\mathrm{al}^{4}$ studies have revealed that more than $50.0 \%$ of asthmatic patients who received no anti-inflammatory treatment have an increased induced sputum eosinophil count. All this studies revealed that asthmatic patients have higher sputum eosinophil count.

\section{Conclusion}

In conclusion sputum eosinophil count becomes elevated in cough variant asthma (CVA). In majority of the cases, sputum eosinophil count is more than $3 \%$. In presence of appropriate background like unproductive cough for more than 8 weeks, and exclusion of other causes, sputum eosinophil count more than $3 \%$ may be considered for the diagnosis of CVA.

\section{References}

1. Matsumoto H, Niimi A, Takemura M, Ueda $T$, Yamaguchi M, Matsuoka H, Jinnai M, Chin K, Mishima M. Features of cough variant asthma and classic asthma during methacholine-induced brochoconstriction: a crosssectional study. Cough. 2009;5(1):3

2. Ayik SÖ, BASOĜLU ÖK, Erdinc M, Bor S, Veral A, Bílgen C. Eosinophilic bronchitis as a cause of chronic cough. Respiratory medicine. 2003;97(6):695-701

3. Niimi A, Amitani R, Suzuki K, Tanaka E, Murayama T, Kuze F. Eosinophilic inflammation in cough variant asthma. European Respiratory Journal. 1998;11(5):1064-9

4. Godon P, Boulet LP, Malo JL, Cartier A, Lemiere C. Assessment and evaluation of symptomatic steroid-naive asthmatics without sputum eosinophilia and their response to inhaled corticosteroids. European Respiratory Journal. 2002;20(6):1364-9

5. Corrao WM, Braman SS, Irwin RS. Chronic cough as the sole presenting manifestation of bronchial asthma. New England Journal of Medicine. 1979;300(12):633-7

6. Alvarez MJ, Olaguibel JM, Garcia BE, Rodriguez A, Tabar AI, Urbiola E. Airway inflammation in asthma and perennial allergic rhinitis. Relationship with nonspecific bronchial responsiveness and maximal airway narrowing. Allergy. 2000;55(4):355-62

7. Scope II, Contraindications B, Training CT, Safety QD. Guidelines for methacholine and exercise challenge testing-1999. American Journal of Respiratory and Critical Care Medicine. 1999;161(1)

8. Bandyopadhyay A, Roy PP, Saha K, Chakraborty S, Jash D, Saha D. Usefulness of induced sputum eosinophil count to assess severity and treatment outcome in asthma patients. Lung India. 2013;30(2):117

9. Bateman E1, Hurd SS, Barnes PJ, Bousquet J, Drazen JM, FitzGerald M, Gibson P, Ohta K, O'byrne P, Pedersen SE, Pizzichini E. Global strategy for asthma management and prevention: GINA executive summary. European Respiratory Journal. 2008;31(1):143-78

10. Oh YB, Mon CH, Kim HY, Lee SM. The diagnostic value of sputum eosinophil counts in patients with chronic cough. Korean Journal of Allergy. 1997;17(2):180-5

11. Dicpinigaitis PV. Chronic cough due to asthma: ACCP evidence-based clinical practice guidelines. CHEST Journal. 2006;129(1 suppl):75S-9S

12. Matsumoto H, Niimi A, Takemura M, Ueda T, Tabuena R, Yamaguchi M, Matsuoka H, Hirai T, Muro S, Ito Y, Mio T, Chin K, Nishiyama H, Mishima M: Prognosis of cough variant asthma: a retrospective analysis. J Asthma 2006, 43: 131-135

13. Yoo Y, Koh YY, Kang H, Yu J, Nah KM, Kim CK. Sputum eosinophil counts and eosinophil cationic protein 
levels in cough-variant asthma and in classic asthma, and their relationships to airway hypersensitivity or maximal airway response to methacholine. Allergy. 2004;59(10):1055-62.

14. Al-Moamary MS, Alhaider SA, Al-Hajjaj MS, AlGhobain MO, Idrees MM, Zeitouni MO, Al-Harbi AS, Al Dabbagh MM, Al-Matar H, Alorainy HS. The Saudi initiative for asthma-2012 update: Guidelines for the diagnosis and management of asthma in adults and children. Annals of thoracic medicine. 2012 Oct $1 ; 7(4): 175$

15. Matsuoka H, Uzu T, Koyama M, Koma Y, Fukumitsu K, Kasai Y, Masuya D, Yoshimatsu H, Suzuki Y. Allergic bronchopulmonary aspergillosis presenting with cough variant asthma with spontaneous remission. Respiratory Medicine CME. 2011;4(4):175-7
16. Harish M, Suryanarayana V. A Prospective Study of Sputum Eosinophils in Acute Exacerbation of Asthma. World Journal of Medical Sciences, 2014;10(2):145-149

17. Richter K, Holz O, Jörres RA, Mücke M, Magnussen H. Sequentially induced sputum in patients with asthma or chronic obstructive pulmonary disease. European Respiratory Journal. 1999;14(3):697-701

18. Good JT, Kolakowski CA, Groshong SD, Murphy JR, Martin RJ. Refractory asthma: importance of bronchoscopy to identify phenotypes and direct therapy. CHEST Journal. 2012;141(3):599-606. 